\title{
PROFESSOR LEOVEGILDO CHAGAS SANTOS (1955): PATRONO DO TERCEIRO GRUPO ESCOLAR DE LIMEIRA, ESTADO DE SÃO PAULO
}

\author{
DOI: http://dx.doi.org/10.1590/2236-3459/67716
}

\author{
Wilson Ricardo Antoniassi de Almeida \\ Universidade Federal de São Carlos, Brasil.
}

\section{$\cos 80$}

\begin{abstract}
Resumo
Este trabalho propõe apresentar a história do patrono da Escola Estadual Professor Leovegildo Chagas Santos, o Terceiro Grupo Escolar de Limeira, estado de São Paulo, que até então se encontrava oculta, já que os alunos, professores e funcionários que atualmente convivem em seus espaços escolares desconheciam a pessoa que identifica e diferencia a instituição escolar das demais, pois inexistia busto, retrato e biografia de seu patrono. A partir da realização de um trabalho de campo que se constituiu numa intensa atividade arqueológica por meio de visitas a arquivos públicos e privados (museus, imprensa, escolas, diretoria de ensino, igreja, familiares, cartórios, município...) desvendou-se aspectos de sua vida pessoal, escolar, profissional e suas contribuições para a sociedade, em específico, para a educação, razões que justificam a sua escolha como designação patronímica para a escola, fazendo-o merecedor de tal homenagem e que poderá permitir à comunidade escolar construir uma identidade e fortalecer o vínculo com a instituição de ensino.

Palavras-chave: Terceiro Grupo Escolar de Limeira, professor Leovegildo Chagas Santos, patrono, história da educação.
\end{abstract}

\section{PROFESSOR LEOVEGILDO CHAGAS SANTOS (1955): PATRON OF THE THIRD SCHOOL GROUP OF LIMEIRA, SÃO PAULO STATE IN BRAZIL}

\begin{abstract}
This paper proposes to present the history of the patron of the State School Professor Leovegildo Chagas Santos, the Third School Group of Limeira, state of São Paulo, that hitherto was hidden, since the students, teachers and employees that currently coexist in their school spaces They did not know the person who identifies and differentiates the school institution from the others, since there was no bust, portrait and biography of his patron. From the realization of a field work that was constituted in an intense archaeological activity by means of visits to public and private archives (museums, press, schools, teaching board, church, relatives, offices, municipality ...) was unveiled Aspects of their personal, school and professional life and their contributions to society, specifically for education, reasons that justify their choice as a patronymic designation for the school, making him worthy of such homage and that may allow the school community Build an identity and strengthen the bond with the educational institution.

Keywords: Third School Group of Limeira, Leovegildo Chagas Santos teacher, patron, history of education.
\end{abstract}


PROFESOR LEOVEGILDO SANTOS DE CHAGAS (1955): PATRÓN DE LA ESCUELA TERCER GRUPO DE LIMEIRA, ESTADO DE SÃO PAULO EN BRASIL

\section{Resumen}

Este trabajo se propone presentar la historia de la patrona de la Escuela Estatal Profesor Leovegildo Chagas Santos, el tercer grupo Escuela de Limeira, Sao Paulo, que hasta entonces había permanecido oculto, como estudiantes, profesores y personal que en la actualidad viven en sus espacios escolares no conocer a la persona que identifica y distingue a la institución educativa del otro busto como inexistente, retrato y biografía de su patrón. A partir de la finalización del trabajo de campo que constituye una actividad arqueológica intensa a través de visitas a los archivos públicos y privados (museos, medios de comunicación, escuelas, tablero de escuela, iglesia, familia, notarías, municipio ...) se desenredaron, aspectos de su vida personal, la escuela, el trabajo y sus contribuciones a la sociedad, en particular, a la educación, las razones de su elección como el nombre patronímico de la escuela, haciéndole merecedor de tal honor y que puede permitir a la comunidad escolar construir una identidad y fortalecer el vínculo con la institución educativa.

Palabras clave: Tercero Grupo Escuela de Limeira, profesor Leovegildo Chagas Santos, patrón, historia de la educación.

\section{PROFESSEUR LEOVEGILDO CHAGAS SANTOS (1955): PATRON DU TROISIĖME GROUPE SCOLAIRE DE LIMEIRA, ÉTAT DE SÃO PAULO AU BRÉSIL.}

\section{Résumé}

Ce travail se propose de présenter l'histoire du patron de l'Ecole d'Etat Professeur Leovegildo Chagas Santos, le troisième groupe École de Limeira, São Paulo, qui jusque-là se tenait caché, comme les étudiants, les professeurs et le personnel qui vivent actuellement dans leurs espaces scolaires ne pas connaître la personne qui identifie et distingue l'établissement d'enseignement de l'autre comme inexistant buste, portrait et la biographie de son patron. De la fin des travaux sur le terrain qui constitue une activité archéologique intense par des visites aux archives publiques et privées (musées, les médias, les écoles, des conseils scolaires, église, famille, notaires, municipalité ...) est démêlé, aspects de sa vie personnelle, l'école, le travail et leurs contributions à la société, en particulier, à l'éducation, les raisons de son choix que le nom patronymique de l'école, ce qui rend digne d'un tel honneur et qui peuvent permettre à la communauté scolaire construire une identité et de renforcer le lien avec l'établissement d'enseignement.

Mots-clés: Troisième groupe École de Limeira, professeur Leovegildo Chagas Santos, patron, histoire de l'éducation. 


\section{Inventário da pesquisa: para fins de introdução}

Suporte de vários símbolos, os primeiros grupos escolares ostentaram representações políticas e sociais, uma apologia ao Estado republicano e à cultura urbana. Nas fachadas, alguns desses símbolos são emblemáticos. $O$ nome GRUPO ESCOLAR, estampado na parte central dos edifícios, confirma a identificação da instituição. A denominação atribuída ao patrono revela um tributo à memória de importantes autoridades políticas. (SOUZA, 1998, p.133-134)

\section{A partir de uma breve interação profissional com a Escola Estadual 1 Professor Leovegildo Chagas Santos, o terceiro grupo escolar de} verifiquei o desconhecimento da história de seu patrono pela comunidade escolar. $\mathrm{Na}$ instituição escolar não existia retrato, busto, ou mesmo uma biografia do patrono.

Diante da ausência de informações referentes ao patrono do estabelecimento de ensino, da minha curiosidade e da necessidade de apresentá-lo à sociedade, mais especificamente à comunidade escolar - pois ao transitar do anonimato para o conhecimento, reconhecimento e compreensão de sua história, é possível construir e fortalecer a identidade e o vínculo entre a sociedade e a escola -, senti-me instigado a desvendar os fatos recônditos sobre sua vida. Esta tarefa que acabara de assumir e que visou à concepção da identidade do patrono excedeu em expectativas de trabalho, tempo despendido e tentativas frustradas até alcançarmos o propósito e, por esta razão, importou-se mencioná-los.

Em virtude da ausência de informações referentes ao patrono na unidade escolar, na Diretoria de Ensino da região de Limeira, na Secretaria de Estado de Educação de São Paulo e de posse apenas do local do início de sua investidura no magistério paulista, bem como de seu próprio nome - o que difere do que exatamente consta em seu registro, abarcando, em razão disso, muito mais dificuldades -, a investigação percorreu as pegadas deixadas no tempo e no espaço. Inicialmente, o itinerário de pesquisa compôsse de dois caminhos: vida profissional, seguindo os passos a partir de sua trajetória profissional, e vida pessoal, buscando os seus familiares e descendentes. Entretanto, em ambos os trajetos percorridos a pesquisa esbarrou em alguns percalços.

Numa primeira tentativa, a pesquisa optou por refazer a sua história de vida pessoal. Para isso foram realizadas consultas em cadastros de falecidos de alguns cemitérios da região, disponíveis virtualmente, pois, inicialmente, pressupunha-se que as suas raízes estivessem próximas. A partir dessa estratégia descobrimos a existência de uma filha - falecida em 2008 - e que a mesma estaria sepultada em São João da Boa Vista. Visitando sua sepultura, foram obtidos os nomes de seu marido, sogro e sogra, pois compartilhavam do mesmo jazigo. De posse desses dados, o secretário do cemitério esclareceu que não se tratava de pessoas da cidade e que outros municípios vizinhos, como Águas da Prata, por ser considerada uma Estância Hidromineral e não possuir cemitério, ali também realizavam os sepultamentos de seus entes.

Sendo essa a única pista disponível, a busca rumou a Águas da Prata. Por ser um

\footnotetext{
${ }^{1}$ Criado em 18 de janeiro de 1944 (SÃO PAULO, 1944a) e instalado em 24 de fevereiro de1944 este grupo escolar funcionou, inicialmente, em salas do porão do segundo grupo escolar de Limeira e somente em 30 de agosto de 1948 as aulas iniciaram em prédio próprio (TERCEIRO GRUPO ESCOLAR DE LIMEIRA, 1944, 1948).
} 
município pouco populoso, logo pudemos dar sequência à investigação, pois após a abordagem feita a alguns moradores da cidade, foi descoberto que um deles não só conhecia a família, como também, como um guia, predispôs-se à orientação do percurso e à intermediação desse encontro. O local combinado era uma fazenda, localizada no bairro da Cascata, no mesmo município. Trajeto muito difícil, situado numa região montanhosa, mas depois de percorridos caminhos estreitos e pedregosos entre as pastagens, plantações, matas e de haver encontrado o administrador da fazenda, o mesmo informou que seus donos - neta do patrono e sua família - residiam em Poços de Caldas, Minas Gerais, sendo que, mediante solicitação, concordou em fornecer seu contato telefônico e endereço.

Diante de uma provável proximidade da solução do mistério, a pesquisa encaminhou-se ao encontro desses familiares. Assim que encontrada a neta do patrono, embora com muita disposição para auxiliar, contou que não havia conhecido o seu avô e que nada sabia sobre ele, pois, quando de sua morte, sequer havia nascido, nem mesmo sabia que uma escola no estado de São Paulo ostentava o seu nome como patrono. Contudo, disse que sua mãe - filha do patrono - apesar da pouca convivência com o pai, já que quando ele veio a falecer ela ainda era uma criança, se ainda fosse viva, ficaria muito feliz e poderia falar muito a seu respeito.

Naquela ocasião, vasculhando alguns documentos da família, a neta do patrono encontrou uma certidão de óbito de seu bisavô materno (sogro do patrono) que, coincidentemente, tinha o mesmo nome de seu avô: Leovigildo Silvério Gomes dos Reis. Antecipou, também, uma pista muito valiosa: que seus ascendentes eram naturais da região de Guaratinguetá. Ao final do encontro, a neta do patrono predispôs-se a contatar outros familiares e a consultar álbuns e documentos da família em busca de fotografias e informações sobre o avô. Pouco tempo depois, retornou contato enviando uma foto de seu avô, apresentada na Figura 2. Todavia, além disso nada mais fora obtido por meio de seus familiares.

Paralelamente, em outra tentativa, a pesquisa empenhou-se em refazer a história de sua vida profissional, visando a localizar o último estabelecimento de ensino em que trabalhara, pois lá estaria seu prontuário funcional com todas as informações cumulativas do período de seu exercício profissional. A única informação que se sabia - a partir dos considerandos que constam no decreto que deu o seu nome ao grupo escolar - referia-se ao início de sua carreira profissional e que, ainda, teria falecido no exercício da profissão.

Diante dessas pistas, consultando arquivos de jornais da época em que iniciou o exercício profissional, foi descoberta a sua primeira nomeação e, a partir daí, bastou seguir seus passos. Foram percorridas todas as escolas para as quais fora nomeado e delas também removido, até que não foi mais possível dar prosseguimento a este percurso de pesquisa, pois o Grupo Escolar de Cachoeira Paulista ${ }^{2}$, para o qual teria sido removido, na região de Guaratinguetá, sofreu um incêndio, pondo fim a todo o seu arquivo, que ficou reduzido a cinzas.

A partir desta constatação e na renitência diante de ambos os percursos, tanto o da vida familiar da referida figura ilustre, como o de sua vida profissional, encaminhandose à região de Guaratinguetá, as buscas foram concentradas nas cidades dali

${ }^{2}$ Atualmente Escola Estadual "Evangelista Rodrigues". 
circunvizinhas, cuja pesquisa recorreu ao suporte propiciado por fontes advindas de arquivos de cemitérios, museus, escolas (as mais antigas), cartórios, diretoria de ensino da região de Guaratinguetá, igreja (Cúria Metropolitana da Arquidiocese da Aparecida) e de acervos da imprensa local, regional e estadual (O Limeirense, Gazeta de Limeira, Correio Paulistano, Diário Oficial do Estado de São Paulo). Essas fontes não supriram por completo a biografia do patrono, nem esvaziaram as possibilidades de emergência de novos dados relevantes, porém forneceram o suficiente para auxiliar-nos a construir a sua identidade.

Como visto, durante esta empreitada com o intuito de desvendar aspectos da vida do patrono, realizou-se uma pesquisa de campo em diversas cidades paulistas, entre elas, pode-se citar Águas da Prata, Aparecida, Cachoeira Paulista, Guaratinguetá, Limeira, Piracicaba, Santa Barbara D’Oeste, São João da Boa Vista, São José do Barreiro e, inclusive Poços de Caldas, pertencente ao estado de Minas Gerais. O fato de a pesquisa ultrapassar os limites do município de Limeira e até do estado de São Paulo não foi surpresa, já que todas as pistas acenavam para que o patrono não provisse do município ou região onde se localiza o estabelecimento de ensino que recebera seu nome, pois, naquele momento, como se apresenta detalhado mais adiante, a própria imprensa local questionou apreensiva e curiosa, juntamente com todo o município, quem era essa pessoa.

Inclusive, foi causa de muita preocupação o mal estado do arquivo de algumas instituições escolares e órgãos públicos visitados, cuja documentação encontrava-se privada de adequado zelo, estando disposta em salas impróprias e deteriorando-se devido ao excesso de umidade decorrente de infiltrações nas paredes ou no teto e à exposição excessiva da luz solar ocasionada pela ausência de cortinas nas janelas.

Agora, antes de situar a história do patrono da instituição escolar, foram tecidas algumas considerações referentes ao processo de concessão da denominação patronímica a próprios públicos, além do destaque ao decurso da mudança patronímica anterior para a atual. Obviamente, não se esgotaram as possibilidades de novas descobertas e, por isso, o que se apresenta a seguir são apenas alguns momentos de sua vida, ficando a sua biografia em aberto para dados complementares.

\section{Denominação Patronímica: professor Leovegildo Chagas Santos}

O procedimento de denominação de um indivíduo ou objeto constitui-se num dispositivo utilizado para identificar e diferenciar cada um no interior de seus grupos correspondentes, cujas nomenclaturas podem expressar algum significado em conformidade com determinado ideal arrolado numa conjectura. Para os próprios públicos, em específico, a escola, não é diferente. Embora o patronímico de uma instituição escolar, atualmente, por vezes, refere-se ao bairro onde a mesma se localiza, geralmente a ela é dado o nome de uma pessoa em homenagem às suas contribuições à sociedade, sobretudo à educação, além de configurar-se como um exemplo de humano e profissional a ser seguido.

Portanto, mais que a identificação e a distinção de natureza, entre o patrono e a sociedade, pode existir um vínculo pois, Leovigildo, ao ter o seu patronímico estampado num próprio público, representa (ou deveria representar) os princípios da população, cuja nomeação atuaria como símbolo de gratidão e respeito. Por isso, importa conhecer o 
patrono da instituição escolar não apenas porque ele lhe dá nome, mas, principalmente, porque entre a sociedade e ele pode figurar-se uma relação, que tem sentido e significado, propensa a estreitar o vínculo entre a escola e a comunidade.

Os próprios públicos são comumente identificados e distinguidos a partir de uma denominação patronímica que os represente, geralmente, reportando-se e prestando homenagem a uma pessoa, prioritariamente, com comprovadas contribuições na área e de caráter idôneo. Na área educacional, o estado de São Paulo oficializou, em 1964 (SÃO PAULO, 1964), a festa do patrono dos professores e normalistas, fato comemorado no dia 15 de maio, referindo-se a São João Batista de La Salle, o seu padroeiro, reconhecido pela Igreja Católica, em 1950. Temos, também, a partir de 2012, o nome do grande educador Paulo Freire como patrono da educação brasileira (BRASIL, 2012) e a sugestão, em 2015 (BRASIL, 2015), de Anísio Teixeira, outro personagem fundamental na história da educação brasileira, como patrono da escola pública.

Já desde os primeiros grupos escolares, conforme o regimento das escolas públicas aprovado em 1894 (SÃO PAULO, 1894), além da identificação inicial a partir da respectiva designação numérica ordinal em cada localidade onde eram criados (como Primeiro Grupo Escolar de Limeira, Segundo Grupo Escolar de Limeira, Terceiro Grupo Escolar de Limeira...), poderiam ser dados nomes especiais, em homenagem aos cidadãos que, por ventura, contribuíssem significativamente para o desenvolvimento da educação popular, principalmente o referente à reunião das escolas.

Assim, a doação de terrenos e prédios para a instalação ou financiamento de construções escolares por industriários e latifundiários constituía prática comum. Muitas vezes, o grupo escolar recebia o nome do político responsável por sua criação ou que se empenhasse na causa pela educação. Esta situação configura a razão pela qual o Terceiro Grupo Escolar de Limeira recebeu a denominação patronímica de "Grupo Escolar Dr. Sebastião Nogueira de Lima"3 - à época, Secretário da Educação e Saúde Pública do Estado de São Paulo. Assim, aos próprios públicos, como ocorreu, também, com o primeiro grupo escolar de Limeira, eram concedidos nomes de pessoas vivas.

Souza (1998) destaca que a estratégia de designar escolas com nomes das pessoas que contribuíssem com a causa da instrução pública, além de angariar recursos para as construções escolares, como tais homens pertenciam à oligarquia econômica e política, ficava reafirmada e legitimada a figura do patrono e da República na memória coletiva. Dessa forma instituiu-se a figura do patrono, personalidade a ser enaltecida e cultuada por professores, alunos e pela sociedade, especialmente nas datas de comemoração do aniversário da escola.

Em Limeira, a prefeitura municipal solicitou, em 1944 (LIMEIRA, 1944), ao diretor do Departamento de Educação, professor Sud Menucci, que fosse dado ao terceiro grupo escolar da cidade o nome de "Dr. Sebastião Nogueira de Lima". A homenagem se justificaria pelos grandes serviços prestados por ele ao município, no setor do ensino público, já que ocupava a chefia da Secretaria da Educação e Saúde Pública. A prefeitura argumentou, ainda, que a aprovação da referida propositura faria perpetuar, numa casa de ensino, o reconhecimento aos benefícios prestados e a gratidão de Limeira àquele homem, que seria exemplo às novas gerações, um símbolo de civismo, de honradez e de

${ }^{3}$ Falecido em 2 de agosto de 1964. 
amor às tradições do município.

Atendendo ao pedido da prefeitura, o interventor federal do estado de São Paulo, Fernando Costa, confere ao terceiro grupo escolar de Limeira (SÃO PAULO, 1944), vigorando a partir de 25 de agosto de 1944, a denominação "Grupo Escolar Dr. Sebastião Nogueira de Lima". Fato inusitado foi que este decreto já havia sido publicado na edição anterior, no entanto, foi republicado, pois constava o referendo do próprio Dr. Sebastião Nogueira de Lima, uma vez que era o atual secretário da pasta, e deveria referir-se ao Secretário da Justiça e Negócios do Interior, Dr. José Adriano Marrey Junior.

Conforme difundido pela imprensa local ${ }^{4}$, o fato causou grande satisfação não apenas para 0 magistério, mas também para a classe política e toda a sociedade limeirense, sobretudo devido ao fato de que, enquanto secretário teria demonstrado interesse pelo desenvolvimento educacional da cidade, fosse criando o Ginásio Estadual, a Escola Profissional Industrial ou a instalação deste grupo escolar.

Importa ressaltar que o empenho do Dr. Sebastião Nogueira de Lima na realização de benfeitorias visando ao progresso do município não possuía apenas caráter político, afinal, contava também com os laços familiares, pois a sua mulher, Zenaide de Barros Camargo Nogueira de Lima pertencia a uma tradicional família limeirense, filha do político e Coronel Flamínio Ferreira de Camargo.

A partir de 1946, facultou-se (BRASIL, 1946) a atribuição de nomes de pessoas já falecidas aos estabelecimentos de ensino primário da federação, considerando como atributos do homenageado a prestação de relevantes serviços à humanidade, ao município, ao estado ou ao país, e cuja vida pública e particular poderia ser apontada às novas gerações como padrão digno de ser imitado. No estado de São Paulo, aos estabelecimentos oficiais de ensino, eram concedidos (SÃO PAULO, 1947) nomes de individualidades nacionais ou estrangeiras, e a respectiva denominação era conferida por ato do chefe do Executivo Estadual, mediante proposta justificada do Secretário do Estado à que estivesse subordinada a instituição.

A designação de pessoas falecidas como patrono de escolas públicas representaria, além da homenagem do Estado à memória dos grandes vultos do passado, um estímulo e um exemplo aos educandos, inculcando-lhes sentimento de respeito e veneração pelos grandes servidores do país, além das virtudes cívicas e sociais. Para o desenvolvimento desses propósitos, em 1955 foi instituído nos estabelecimentos de ensino do Estado, o Dia do Patrono (SÃO PAULO, 1955b), de celebração obrigatória, a ser comemorada anual e preferencialmente no dia do nascimento do homenageado ou em data escolhida pela direção, aprovada pela Secretaria de Educação, quando coincidisse com o período de férias.

Cada escola com denominação patronímica deveria inaugurar, conservar e manter em local de honra o busto ou o retrato do patrono (SÃO PAULO, 1955b; SÃO PAULO, 1976), divulgando e afixando em local visível e emoldurado a sua biografia, com as datas de nascimento, falecimento, filiação, naturalidade, atividades que o recomendam à estima pública, trabalhos realizados e obras publicadas. A festa do dia do patrono constituir-se-ia de solenidades cívicas, culturais, esportivas e literomusicais, com ênfase na vida e obra do homenageado.

${ }^{4}$ GAZETA DE LIMEIRA, 27 de agosto de 1944. 
Ainda em 1955, com a proibição da concessão de nomes de pessoas vivas a próprios públicos do Estado (SÃO PAULO, 1955a) e mediante a necessidade da adoção de providências para o cumprimento dessa disposição, o então governador do Estado, Jânio Quadros, revogou o decreto que deu a denominação "Dr. Sebastião Nogueira de Lima" ao Terceiro Grupo Escolar de Limeira e, sem aguardar sugestão do município, denominou-o de "Professor Leovegildo Chagas Santos" (SÃO PAULO, 1955c)5 , a vigorar a partir de 19 de outubro de 1955.

Contudo, mediante divulgação pela imprensa local ${ }^{6}$, o município de Limeira não conhecia a figura do professor homenageado, pois não se tratava de representante do magistério primário do município. Uma professora (MIGUEL, 2014) que lecionou no grupo escolar nesse tempo conta que "[...] quando alterou a denominação do grupo escolar para Leovegildo Chagas Santos, o diretor solicitou à Secretaria de Educação e Saúde Pública informações referentes ao patrono, pois nada era sabido sobre ele", e como não permaneceu na escola nos anos posteriores, não pode informar se obteve resposta sobre a referida questão. A maior proximidade do novo patrono com Limeira deve-se ao fato de ele haver lecionado, na primeira metade da década de 1920, em Santa Bárbara D'Oeste, município que, juntamente com Limeira, pertencia à mesma delegacia regional de ensino, com sede no município de Piracicaba.

A apresentação do professor Leovegildo Chagas Santos à população restringia apenas a informações baseadas nos considerandos apresentados no decreto (SÃO PAULO, 1955c) da referida denominação:

Considerando que o professor Leovegildo Chagas Santos, iniciado no magistério público a 31 de janeiro de 1908, veio a falecer no cumprimento de seu dever; Considerando que, na sua longa carreira dedicada à ilustração da nossa infância, foi esse mestre paradigma de devotamento, de esforço, e de amor à sagrada causa do ensino.

Embora Limeira esperasse a perpetuação, em seu estabelecimento de ensino, de uma denominação que simbolizasse e exprimisse a gratidão, a admiração e o respeito de toda população à memória daqueles professores que dignificaram e enobreceram o próprio ensino no município7, a partir do julgamento das menções apontadas nos considerandos do decreto, também reconhecia os méritos do professor Leovegildo Chagas Santos e considerava como merecida a homenagem à sua memória.

No ano seguinte, em 15 de novembro de 1956, após a mudança patronímica, aconteceu no estabelecimento do Grupo Escolar Professor Leovegildo Chagas Santos uma solenidade para a inauguração do retrato de seu patrono ${ }^{8}$, além de outros vultos da história da pátria e do ensino limeirense como patronos de cada uma das salas existentes na escola: Princesa Isabel, Dom Pedro II, José Joaquim da Silva Xavier (Tiradentes), Marechal Deodoro da Fonseca, Madre Inocêncio Lima, Irmã Maria Ângela, professora Isabel Baptista de Oliveira, professora Irene Alves de Toledo, professor Aderbal Castro, Dr. Otávio Lopes Castello Branco e Antônio Tenório da Rocha Brito. Conforme lembra

\footnotetext{
${ }^{5}$ A denominação da escola foi dada por decreto do governador, de forma que não passou pela Assembleia Legislativa.

6 O LIMEIRENSE, 23 de outubro de 1955.

7 O LIMEIRENSE, 23 de outubro de 1955.

${ }^{8}$ O LIMEIRENSE, 15 de novembro de 1956.
} 
uma aluna (CAMPOS, 2014a) participante desse evento, durante a solenidade, os quadros dos patronos encontravam-se todos expostos no palco.

Mais tarde (SÃO PAULO, 1988), em 1988, considerando a importância do conhecimento de aspectos da vida do patrono de cada unidade escolar, o respeito que se deve ter a ele por suas ações dignificantes e perante a necessidade de conservar, na memória da posteridade, a imagem do patrono para os efeitos culturais, a Secretaria de Educação instituiu nas delegacias de ensino o Arquivo do Patrono. Para compor este arquivo, as escolas deveriam promover concursos de pesquisa sobre a vida de seus respectivos patronos.

Apesar da inauguração de seu patrono na escola, em visita recente à instituição pesquisada, verificamos que não há exposição de busto nem retrato do homenageado e, conforme os relatos de alunos, professores, diretores e funcionários de períodos distintos da existência da instituição de ensino, evidenciou-se que não houve a preocupação com a promoção da difusão da biografia de seu patrono, pois todos foram unânimes, afirmando desconhecê-lo, sendo ausentes de informações sobre sua vida e obra, além de nunca havê-lo visualizado sequer por fotografia ou busto, mas que tinham interesse em conhecê-lo. Ora, mesmo com a criação, na delegacia de ensino, de um arquivo específico para os patronos das escolas, quando solicitadas informações e realizada a pesquisa em seu acervo, nada puderam esclarecer nem ser encontrado.

Perguntados se conheciam o patrono da escola, foram obtidas respostas semelhantes de alguns depoentes, tais como:

[...]. Jamais consegui informações, nem com os mais antigos professores e
diretores, sobre o patrono, apesar de minha grande curiosidade. (VITTA, 2014);
[...]. Durante o período que trabalhamos na escola nada soubemos sobre a sua
biografia, exceto que foi professor. Sempre quisemos conhecer a sua história, mas
pela ausência de fontes na escola nunca fomos informados. (CAMPOS; CARILE;
OLIVEIRA, 2014a; CAMPOS; CARILE, 2014b; MARCHESIN; SANTOS; SORG,
2014); [...] Ninguém nunca apresentou quem foi e o que ele fez. Não o
conhecemos nem por fotografia. Sabemos apenas que dá nome à escola. (LUIZ,
2014b; LIMA; PORFIRIO, 2014) [...]. Não conhecemos a sua história, mas temos
vontade em aprender, inclusive nunca vimos o seu retrato. (PEREIRA;
SELINGARDI, 2014; LOPES, 2014b); [...]. Não sabemos nada sobre ele e quando
perguntamos na unidade escolar ninguém soube responder. (FORTI;
RODRIGUES, STEFANEL, 2014)

Embora todos os depoentes afirmassem o desconhecimento da pessoa que dá nome à escola, alguns lembraram que, até o início da década de 1980, cada sala do prédio possuía um patrono, acompanhada da respectiva fotografia e de uma breve biografia (RAMOS, 2014; CARILE; CAMPOS, 2014a). Nesta escola, esta prática de denominação patronímica das dependências da escola se perdeu em algum momento, ao longo do tempo, deixando de ser cultuada, pois não existem mais fotografias nem biografias sequer compondo o acervo do arquivo escolar.

Atualmente, o homenageado, candidato a patrono de próprios públicos, deve ser pessoa falecida ou com mais de 65 anos e, quando se tratar de estabelecimento de ensino, a proposta deve-se acompanhar de abaixo-assinado com, no mínimo, assinaturas de quatrocentos moradores da região atendida pela escola, ou da manifestação de apoio do Conselho de Escola, priorizando nome de educador ou educadora cuja vida esteja vinculada à comunidade em que se situe a escola e, quando não, que sua biografia 
estimule os educandos ao estudo (SÃO PAULO, 2012).

A abertura para a participação da comunidade escolar ou do Conselho de Escola na escolha do patrono da escola apresenta-se coerente e justa, já que a instituição de ensino fará parte do cotidiano de suas vidas, seja porque convivem diariamente com os seus espaços escolares enquanto estudantes ou profissionais da educação, seja porque a escola, assim como cada rua e a praça, compreende o bairro.

\section{Vida pessoal}

Ainda que a denominação do grupo escolar seja Professor Leovegildo Chagas Santos, em todos os documentos pesquisados como certidão de nascimento, de batismo, de óbito ou em livros de movimento ou de ponto das escolas em que lecionou, a escrita correta de seu nome, conforme ele próprio o assinava, usando caneta bico-de-pena, como exibido na Figura 1, é Leovigildo das Chagas Santos.

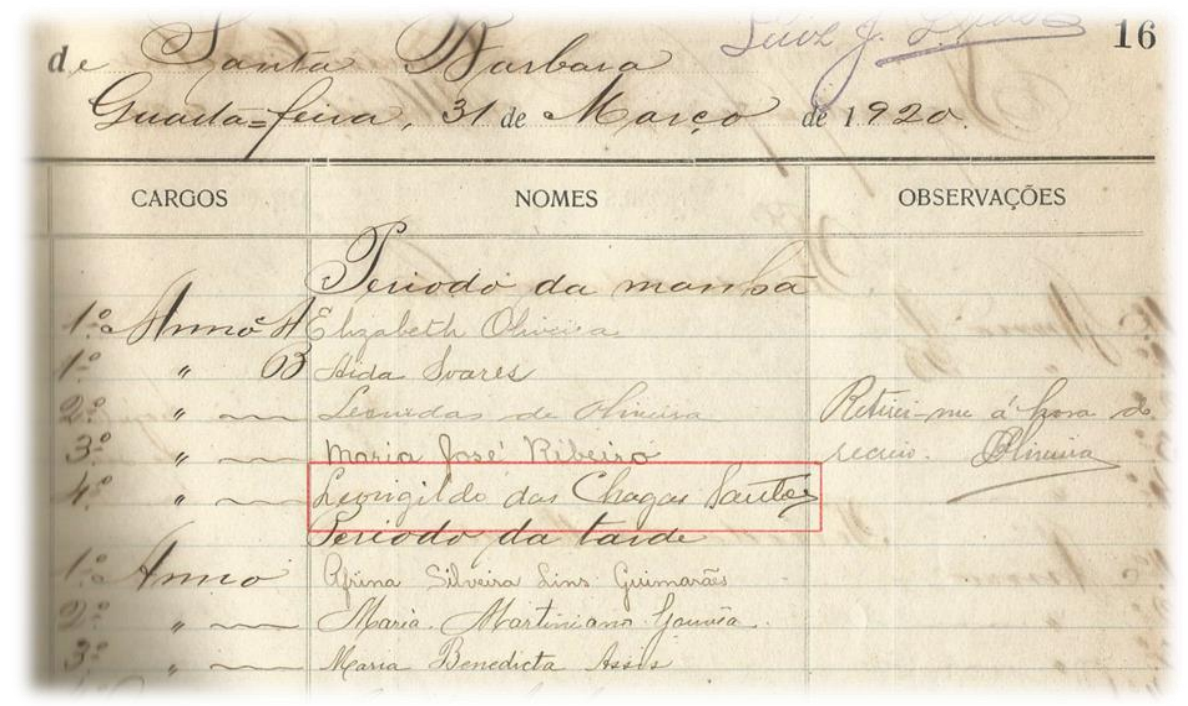

Figura 1 - Rubrica do professor Leovigildo das Chagas Santos, 1920.

Fonte: Grupo Escolar de Santa Barbara d'oeste ${ }^{9}, 1920$.

Quanto aos aspectos gráficos e fonéticos, além de a segunda sílaba do prenome sofrer a permutação do $i$ pelo $e$, ocorreu a supressão da contração das que liga $o$ prenome ao sobrenome, o que tornou a sua escrita e pronúncia mais rápida, pois são, respectivamente, três caracteres e um fonema a menos. Ora, e daí? Embora as alterações no nome do patrono não se caracterizarem como relevantes, para a pesquisa de campo elas foram muito significativas, pois dificultaram a busca por informações, principalmente em arquivos virtuais.

Leovigildo das Chagas Santos, natural de Guaratinguetá, estado de São Paulo, nasceu em 22 de abril de 1885, filho de Francisco das Chagas Santos ${ }^{10}$, comerciante, e Maria das Dores dos Reis, doméstica, tendo outros seis irmãos: Benedicta, nascida (ARQUIDIOCESE DE APARECIDA, 1880) aos 24 de junho de 1.880 (4 anos mais velha),

\footnotetext{
9 Primeiro Grupo Escolar de Santa Barbara D'Oeste, atualmente, Escola Estadual José Gabriel de Oliveira.

10 Falecido em 25 de setembro de 1894, aos 45 anos (SERVIÇO DE REGISTRO CIVIL DO 1ㅇ SUBDISTRITO DE GUARATINGUETÁ, 1894).
} 
Virgilia ( 3 anos mais velha), Arnopho (um ano mais velho), Maria Antonietta e Maria Amélia, nascidas (ARQUIDIOCESE DE APARECIDA, 1888) em 8 de maio de 1.888 (3 anos mais jovens) e Antônia, nascida (ARQUIDIOCESE DE APARECIDA, 1890) aos 22 de maio de 1.890 (5 anos mais jovem). Em 25 de setembro de 1894 (MUSEU FREI GALVÃO, 1894), aos 9 anos de idade, Leovigildo e seus irmãos tornaram-se órfãos de pai, incumbindo a sua mãe da laboriosa tarefa de cuidar de sete crianças.

De religião católica, foi batizado na Paróquia de Santo Antônio, em Guaratinguetá, estado de São Paulo, aos treze de junho de 1886, sendo padrinhos Antônio Ferreira da Costa e Maria Tereza da Conceição. (ARQUIDIOCESE DE APARECIDA, 1886) Foram seus avós paternos, Francisco Manoel da Silva Pombo e Marianna do Espiríto Santos, e a avó materna Gertrudes Leopoldina da Conceição (ARQUIDIOCESE DE APARECIDA, 1879).

Casou-se (SERVIÇO DE REGISTRO CIVIL DO 1ㅇ SUBDISTRITO DE GUARATINGUETÁ, 1925) com Emília dos Reis Santos, doméstica, natural de São José do Barreiro, filha de Leovigildo Silvério Gomes dos Reis e Maria Olivia Gomes dos Reis, com quem teve dois filhos, Yolanda Reis Santos ${ }^{11}$, nascida em 03 de junho de 1914 e falecida em 06 de março de 2008, e Hilton Reis Santos, nascido (ARQUIDIOCESE DE APARECIDA, 1924) em 21 de agosto de 1924 e falecido em 18 de fevereiro de 1968, que também vieram a ser professores. Residia com a esposa e filhos em Cachoeira Paulista, estado de São Paulo.

Apresenta-se, na Figura 2, o visual de Leovigildo Chagas Santos durante a década de 1900. Homem de pele clara e cabelos escuros, aqui ele aparece elegantemente trajado com a cabeça e o olhar um pouco deslocados à sua esquerda, e assim como a maioria dos homens, portava bigode, característica comum à cultura masculina até a primeira metade do século $X X$, pois nas últimas décadas entrou em desuso diante de uma progressiva necessidade de "limpeza visual".

${ }^{11}$ Após o casamento o seu nome passou a ser Yolanda Reis Santos Rodrigues. 


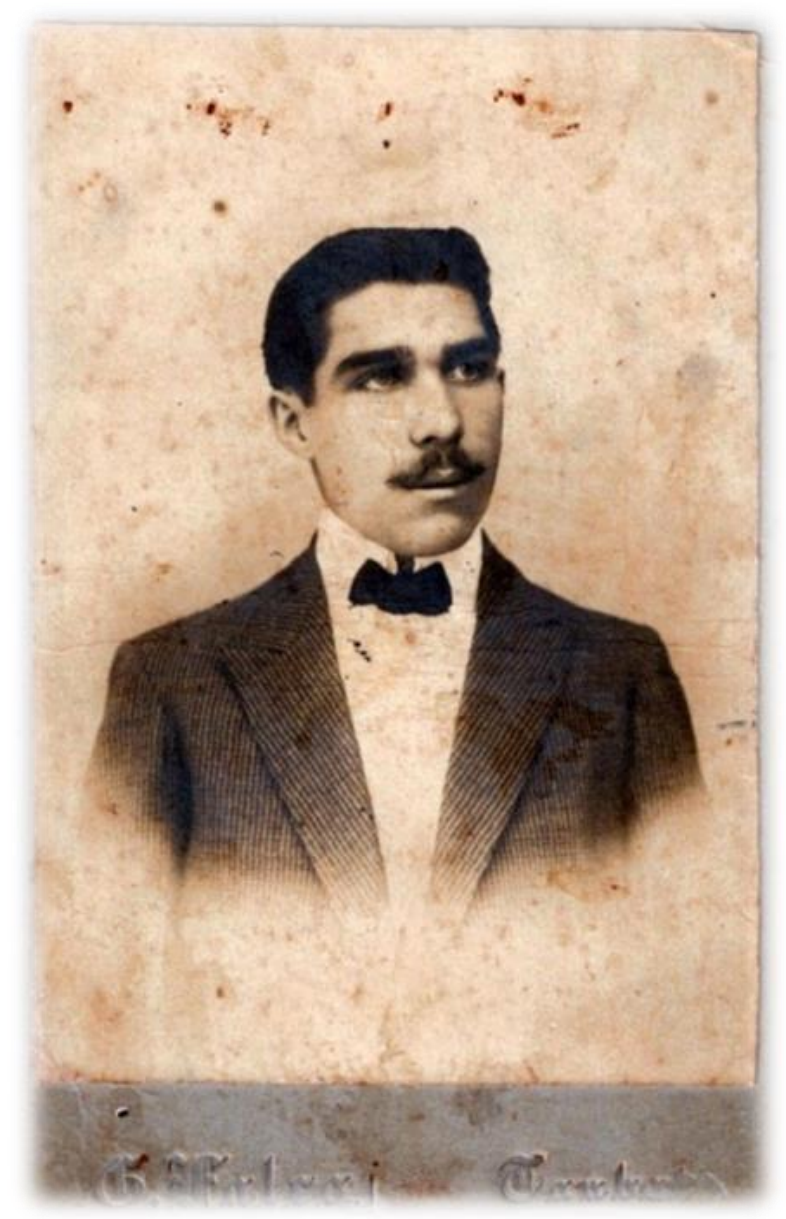

Figura 2 - Leovigildo das Chagas Santos, 1906.

Fonte: Acervo de Maria Acácia Rodrigues Fernandes e Luiz Eugênio Fernandes. ${ }^{12}$

Em decorrência de um colapso cardíaco, veio a falecer (SERVIÇO DE REGISTRO CIVIL DO 1 SUBDISTRITO DE GUARATINGUETÁ, 1925) às 22 horas de 30 de janeiro de 1925, aos 39 anos, em Rezende, estado do Rio de Janeiro, sendo sepultado, no dia seguinte, no cemitério dos Passos em Guaratinguetá-SP. Quando morreu (CORREIO PAULISTANO, 12 de fevereiro de 1925), encontrava-se em trânsito de viagem de regresso para Guaratinguetá de São José do Barreiro, onde buscava tratamento para a sua saúde, minada por insidiosa moléstia. Os seus despojos foram transportados em carro mortuário no trem expresso para Guaratinguetá e, ao passar o féretro por Cachoeira Paulista, onde atuava como adjunto do grupo escolar, seus colegas, representados por uma comissão de professores, depositaram sobre ele uma rica coroa de flores, com uma sentida dedicatória e apresentação de pêsames a sua família.

Sua morte foi muito sentida e teve grande repercussão nas cidades de Cachoeira Paulista, onde trabalhara e residira, e em Guaratinguetá, onde nascera, e onde o enterro foi acompanhado por muitas pessoas dentre familiares, amigos, alunos, colegas e autoridades, pois "[...] era muito estimado e se impusera pelo seu carácter, pela sua modéstia e pela sua bondade. Era um professor competente, dedicado, trabalhador e por

12 Respectivamente, neta de Leovigildo das Chagas Santos e seu marido. 
isso perde a instrucção pública um funccionário modelar"13.

No momento de sua morte (SERVIÇO DE REGISTRO CIVIL DO 1ㅇ SUBDISTRITO DE GUARATINGUETÁ; MUSEU FREI GALVÃO, 1928), sua filha estava com 10 anos e seu filho com apenas 5 meses. Sua esposa viria a falecer pouco tempo depois, em 16 de setembro de 1928, aos 40 anos, em consequência de uma tuberculose crônica generalizada. Com a morte de Emília, o seu irmão e tio das crianças, Alberto Silvério Gomes dos Reis, assumiu a tutoria dos filhos.

\section{Vida escolar}

Leovigildo foi matriculado (GRUPO ESCOLAR DR. FLAMÍNIO LESSA, 1898) no Grupo Escolar "Dr. Flamínio Lessa" - Primeiro Grupo Escolar de Guaratinguetá tardiamente, aos 11 anos, em 01 de junho de 1896, onde estudou juntamente com uma de suas irmãs, Virgília dos Santos Reis, três anos mais velha, matriculada em 01 de maio do mesmo ano. No grupo escolar cursou as matérias que constituem o Curso Preliminar, realizando o exame final dia 30 de novembro de 1898, em que fora aprovado e a ele conferido o diploma de Habilitação Geral do Curso.

Iniciou o curso de formação de professores, em 1903, na Escola Complementar de Guaratinguetá, tendo sido formando da primeira turma, diplomou-se professor primário em 1906, aos 21 anos. As escolas complementares (SÃO PAULO, 1900) formavam professores com habilitação no magistério primário, com as mesmas vantagens concedidas aos diplomados pela Escola Normal, mediante a realização de prática de ensino em qualquer grupo escolar do Estado.

$\mathrm{Na}$ Figura 3 são apresentados os retratos dos professorandos da turma de 1906. Este quadro, assim como os de outras turmas subsequentes, encontra-se emoldurado e exposto no anfiteatro da antiga Escola Complementar de Guaratinguetá. O recém complementarista, Leovigildo - situa-se na 3a posição, da esquerda para a direita, na penúltima linha.

${ }^{13}$ CORREIO PAULISTANO, 12 de fevereiro de 1925. 


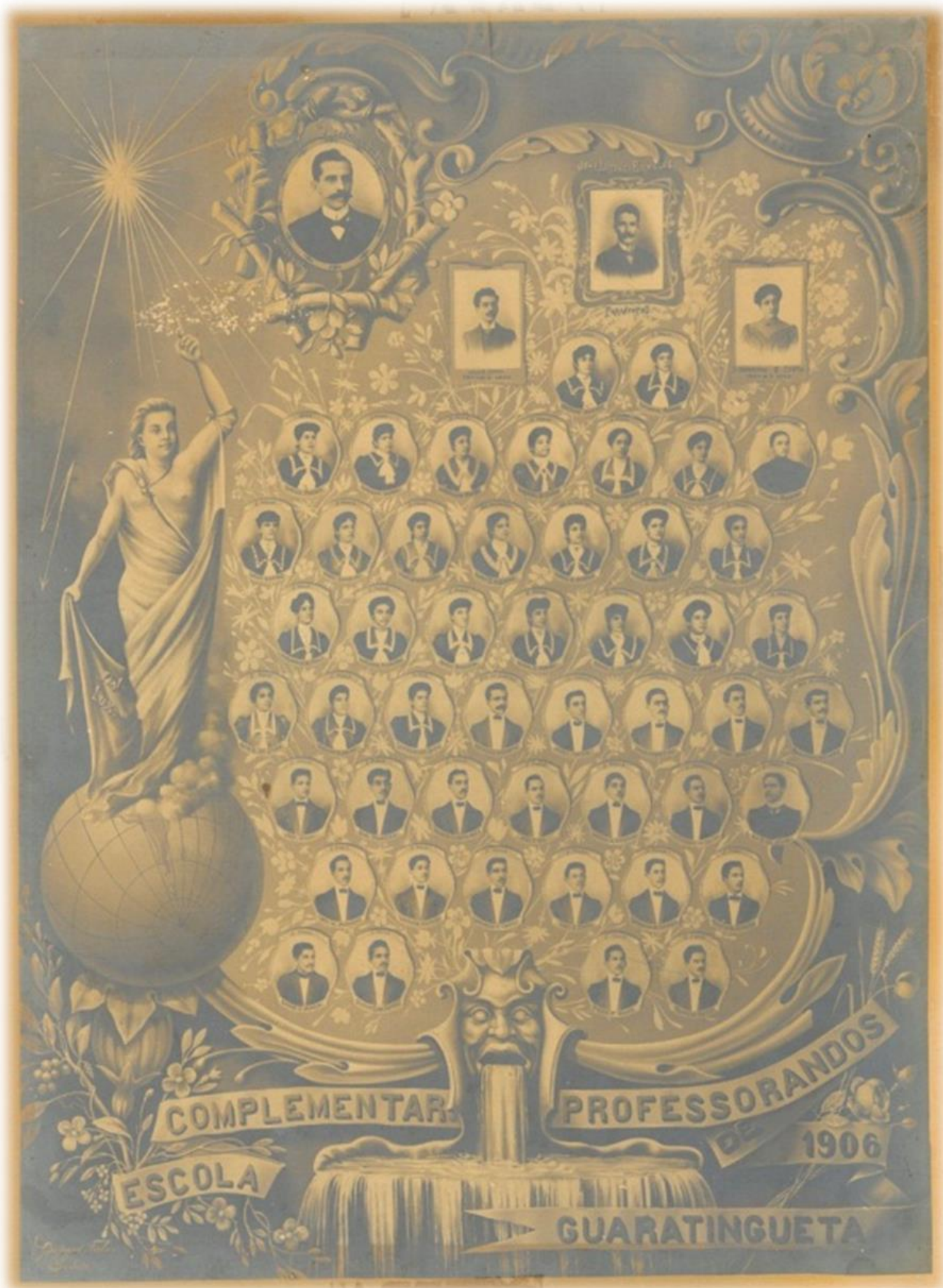

Figura 3 - Primeira turma de formandos da Escola Complementar de Guaratinguetá, 1906.

Fonte: Escola Complementar de Guaratinguetá - atual Escola Estadual Conselheiro Rodrigues Alves.

Compunha a primeira turma de professorandos da Escola Complementar, iniciando na parte superior, da esquerda para a direita, o diretor: professor José Carneiro da Silva (canto superior esquerdo); paraninfo da turma: professor João Lourenço Rodrigues (superior, ao centro); professor do $4^{\circ}$ ano: Júlio Batista da Costa (um pouco 
abaixo, ao lado esquerdo do professor paraninfo); professora do $4^{\circ}$ ano: Minervina Soares Costa (um pouco abaixo, ao lado direito do paraninfo); professorandos: 1a linha (logo abaixo do paraninfo): Adelina Bastos (1 $\left.{ }^{\mathrm{a}}\right)$; Alfonsina Pereira (2a); 2a linha: Davina Passos

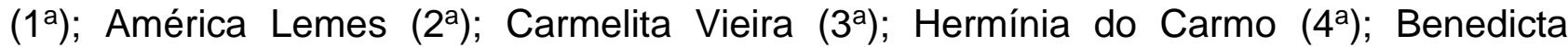
Marcondes do Amaral (5a); Josephina de Albuquerque Lima (6a); Adelaide Pourchet (7a); 3a linha: Luiza Xavier (1 $\left.{ }^{a}\right)$; Maria Catão Filha $\left(2^{a}\right)$; Maria José de Andrade $\left(3^{a}\right)$; Maria Salomé de Albuquerque Lima (4⿳a); Maria Antonietta Merello (5a); Maria G. de Mattos Filha $\left(6^{\mathrm{a}}\right)$; Marietta Costa $\left(7^{\mathrm{a}}\right)$; 4a linha: Marianna de Moura Mello (1a); Marianna Augusta Fernandes (2a); Maria das Dores Gallicho (3a); Maria O. Pereira (4a); Noemi da Silva Penna (5a); Hercília Rangel de Camargo (6a); Rosalina Juliano (7a); 5a linha: Ruth R. da

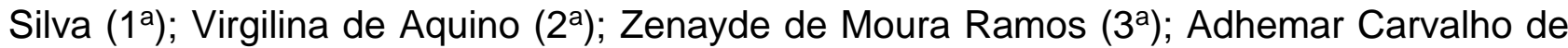
Campos (4); Alcides Coutinho $\left(5^{\circ}\right)$; Ângelo Martino $\left(6^{\circ}\right)$; Anísio Novaes $\left(7^{\circ}\right)$; Euclydes Carvalho de Campos $\left(8^{\circ}\right)$; 6a linha: José Silva $\left(1^{\circ}\right)$; João Palazzo $\left(2^{\circ}\right)$; Joaquim dos Santos Magalhães $\left(3^{\circ}\right)$; José Vieira Vaz $\left(4^{\circ}\right)$; Justino Antunes Sobrinho $\left(5^{\circ}\right)$; Luttgardes de Castro $\left(6^{\circ}\right)$; Gil T. da Silva $\left(7^{\circ}\right)$; 7a linha: Luiz Marcondes Guimarães $\left(1^{\circ}\right)$; Lindolpho D'Oliveira $\left(2^{\circ}\right)$; Leovigildo das Chagas Santos $\left(3^{\circ}\right)$; Luiz de Castro Pinto $\left(4^{\circ}\right)$; Liberalino de Oliveira $\left(5^{\circ}\right)$; Malvino de Oliveira $\left(6^{\circ}\right)$; $8^{a}$ linha: Ramiro C. Gloria $\left(1^{\circ}\right)$; Silvino Xisto dos Santos $\left(2^{\circ}\right)$; Plinio P. Braga $\left(3^{\circ}\right)$; Walfrido Nazianzeno Maciel $\left(4^{\circ}\right)$.

Assim como Leovegildo das Chagas Santos, muitos de seus colegas tiveram os seus nomes estampados na fachada principal de escolas. Podemos verificar nessa turma que, dos 48 professorandos, as mulheres e os homens correspondem, respectivamente, a $54 \%$ e $46 \%$, cujos dados evidenciam a superação da profissionalização feminina no magistério em relação à masculina.

\section{Vida profissional e social}

Leovigildo das Chagas Santos e outros 22 complementaristas, em cumprimento à prática $^{14}$ de ensino constante do currículo, foram autorizados (SÃO PAULO, 1906), ao final do curso, durante o ano de 1907, a praticarem nos grupos escolares de Guaratinguetá, São Roque, Campinas e Taubaté.

Integrante de tradicional família paulista, ligada por muitos vínculos ao magistério, dentre alguns irmãos, cunhados e sobrinhos, também influenciou na escolha profissional de seus filhos e netos, os quais vieram a exercer o mesmo ofício.

Complementarista, iniciou a carreira no magistério público do estado de São Paulo em 31 de janeiro de 1908, quando foi nomeado (SÃO PAULO, 1908) para atuar na escola isolada ${ }^{15}$ estadual no bairro Serra do José Pedro, em São José do Barreiro. Logo

\footnotetext{
${ }^{14}$ A proliferação de grupos escolares pelo território estadual esbarrou numa das questões que foi empecilho para a educação durante todo o decorrer do Império: a falta de professores qualificados. Como medida para obter um maior número de professores habilitados ao ensino primário, a partir de 1895, estabeleceuse que os alunos concluintes do curso complementar ou do Ginásio do Estado que realizassem um ano de prática de ensino nas escolas-modelo estaduais, poderiam ser nomeados professores preliminares, com as mesmas vantagens concedidas aos diplomados pela escola Normal (SÃO PAULO, 1895). As escolasmodelo foram criadas para a prática de ensino dos alunos candidatos à regência de cadeiras. Funcionavam anexas à Escola Normal, com turmas de ambos os sexos, equiparadas ás demais escolas de instrução primária.

15 Com a criação dos grupos escolares e das escolas reunidas, essa designação foi utilizada para caracterizar as escolas de primeiras letras (elementares ou preliminares) que funcionavam de forma unitária, ou seja, referia a escola formada por uma só classe e esta multisseriada e unidocente. O uso
} 
depois (SÃO PAULO, 1910), em 17 de janeiro de 1910, foi removido para a terceira escola masculina urbana da mesma cidade.

Durante o período que esteve em São José do Barreiro, o professor Leovigildo, em 18 de março de 1915, foi escolhido ${ }^{16}$ dentre os sócios, além de Fausto C. Vianna e Ramiro Martins, para compor a nova diretoria da Sociedade Beneficente Municipal Barreirense e também organizou e fundou17, em 1917, o Barreiro Foot-Ball Club, sendo um de seus diretores, juntamente com Antônio de Santa Marinha, Adhemar Campos e Benedicto Pereira Martins.

A próprio pedido, em 23 de março de 1920, foi exonerado (SÃO PAULO, 1920) da terceira escola urbana de São José do Barreiro e nomeado para o cargo de adjunto no Grupo Escolar de Santa Barbara D'Oeste. Assumiu em $1922^{18}$, interinamente, por um mês, a direção do Grupo Escolar de Santa Barbara D'Oeste, durante o impedimento de seu diretor, o professor Antônio de Arruda Ribeiro, licenciado para tratamento de saúde em decorrência de uma enfermidade (gripe), da que já se encontrava em recuperação.

Atuou como escoteiro na Comissão Regional de Escoteiros de Santa Barbara D'Oeste ${ }^{19}$, filiada à Associação Brasileira de Escoteiros, sob o número 153, integrando a sua diretoria, ocupando a função de delegado técnico. Neste momento, a comissão de escoteiros estava em constante progresso: dos 70 que recebiam instruções diariamente, sem prejuízo das aulas do grupo escolar, havia 45 escoteiros fardados. ${ }^{20}$

Ao iniciar o ano letivo de 1923, devido à supressão de duas classes do curso médio no grupo escolar, o professor Leovigildo tornou-se um dos adjuntos adidos. ${ }^{21}$ Por encontrar-se nessa situação, foi nomeado para reger, em comissão, a escola masculina rural convertida para escola mista rural que compunha as Escolas Reunidas ${ }^{22}$ da Usina de São Pedro no mesmo município ${ }^{23}$, em substituição a uma professora licenciada ${ }^{24}$. Permaneceu neste grupo escolar até 01 de abril de $1924^{25}$, quando foi removido para o Grupo Escolar de Cachoeira Paulista (GRUPO ESCOLAR DE SANTA BARBARA D'OESTE, 1924), no qual atuou e dedicou-se ao magistério primário até a sua precoce morte, perfazendo 17 anos de contribuição à instrução pública.

\section{Considerações finais}

Mediante o exposto e dentre algumas reflexões dele emergidas, importa destacar que não há sentido denominar uma instituição de ensino com o nome de uma pessoa e esta ser desconhecida pela comunidade escolar, pois, não fosse para homenagear

desse termo na legislação paulista surgiu a partir de 1894, no regimento interno das escolas públicas (SÃO PAULO, 1894).

16 CORREIO PAULISTANO, 19 de março de 1915.

17 CORREIO PAULISTANO, 18 de outubro de 1917.

18 CORREIO PAULISTANO, 11 de setembro de 1922.

19 CORREIO PAULISTANO, 10 de agosto de 1922.

20 CORREIO PAULISTANO, 11 de setembro de 1922.

21 CORREIO PAULISTANO, 01 de março de 1923.

22 As escolas reunidas também se caracterizavam como escolas graduadas, porém, representavam estabelecimentos de ensino intermediários entre as escolas isoladas e o grupo escolar, os quais surgiram como uma solução provisória e de baixo custo para atender a demanda da educação popular em locais com grande potencial para a futura instalação de um grupo escolar.

${ }^{23}$ CORREIO PAULISTANO, 06 de abril de 1923.

24 CORREIO PAULISTANO, 07 de maio de 1923.

25 CORREIO PAULISTANO, 12 de fevereiro de 1925. 
alguém que tivera um vínculo para com a sociedade e tê-lo como um exemplo de humano e profissional a ser seguido, não se justificaria a atribuição de uma denominação correspondente a uma pessoa verídica quando um pseudônimo qualquer poderia ser atribuído.

Embora a atual denominação do terceiro grupo escolar de Limeira tenha se caracterizado como um ato político, pois o governo estadual não solicitou ao município a sugestão de um nome que representasse a sociedade local, em específico, o magistério limeirense, cuja preocupação maior foi apenas identificar a instituição de ensino, diante da exposição da história de vida profissional e social do patrono tem-se um repertório de razões que justificam e legitimam a sua escolha como patrono, o que o faz digno e merecedor de tal homenagem.

Portanto, apesar de não existir nenhum laço entre o patrono Leovegildo Chagas Santos, a sociedade e o magistério do município de Limeira, já que não era limeirense e nunca residiu nem trabalhou no município, conhecendo-se a sua história, a comunidade escolar, além de dispor de um nome para identificar e diferenciar a instituição de ensino à qual pertencem suas congêneres, contará com a denominação de alguém que agora apresenta significado para que possa ser respeitado e representá-la, assim viabilizando a construção e a intensificação de uma identidade e do vínculo com a escola. ${ }^{26}$

\section{Referências}

ARQUIDIOCESE DE APARECIDA. Cúria Metropolitana. Paróquia Santo Antonio, Guaratinguetá, estado de São Paulo. Certidão de Batismo, cujo registro está lavrado no livro 35, às folhas 69 , último termo da folha, 1.880 .

Cúria Metropolitana. Paróquia Santo Antonio, Guaratinguetá, estado de São Paulo. Certidão de Casamento, cujo registro está lavrado no livro 22, às folhas 29 vs., 10 termo da folha, 1.879 .

. Cúria Metropolitana. Paróquia Santo Antonio, Guaratinguetá, estado de São Paulo. Certidão de Batismo, cujo registro está lavrado no livro 41, às folhas 79 , terceiro termo da folha, 1.888 .

Cúria Metropolitana. Paróquia Santo Antonio, Guaratinguetá, estado de São Paulo. Certidão de Batismo, cujo registro está lavrado no livro 40, às folhas 62,60 ormo da folha, 1886.

Cúria Metropolitana. Paróquia Santo Antonio, Guaratinguetá, estado de São Paulo. Certidão de Batismo, cujo registro está lavrado no livro 41, às folhas 568, sétimo termo da folha, 1.890 .

. Cúria Metropolitana. Paróquia Santo Antonio, Guaratinguetá, estado de São Paulo. Certidão de Batismo, cujo registro está lavrado no livro 71, folhas 138, termo 488 da folha, 1.924.

BRASIL. Decreto-lei no: 8.529, de 2 de janeiro de 1946. Lei Orgânica do Ensino Primário. Disponível em: <http://www2.camara.leg.br/legin/fed/declei/1940-1949/decreto-lei-8529-2janeiro-1946-458442-publicacaooriginal-1-pe.html>. Acesso em: 10 mai. 2015.

. Lei no: 12.612, de 13 de abril de 2012. Declara o educador Paulo Freire Patrono da Educação Brasileira. Disponível em: <http://www.planalto.gov.br/ccivil_03/_Ato2011-

${ }^{26}$ No dia 20 de outubro de 2016, a partir de informações e materiais obtidos por essa pesquisa e fornecidos à escola, aconteceu a reinauguração do retrato e da biografia de seu patrono. 
2014/2012/Lei/L12612.htm>. Acesso em: 13 mai. 2015.

Projeto de lei no: 1.133, de 14 de abril de 2015. Declara Anísio Teixeira Patrono da Escola Pública Brasileira. Disponível em:

<http://www.camara.gov.br/proposicoesWeb/fichadetramitacao?idProposicao=1203358>. Acesso em: 20 de junho de 2015.

CAMPOS, Maria Luiza de. Aluna de 1952 a 1956 e professora em 1964 e de 1980 a 1994. Terceiro Grupo Escolar. Limeira, 04 fev. 2014a. Depoimento concedido a Wilson Ricardo Antoniassi de Almeida.

CAMPOS, Vera Lucia de. Aluna de 1958 a 1962 e professora de 1987 a 1995. Terceiro Grupo Escolar. Limeira, 04 fev. 2014b. Depoimento concedido a Wilson Ricardo Antoniassi de Almeida.

CARILE, José Archangelo. Professor, vice-diretor e diretor de 1980 a 2016. Terceiro Grupo Escolar. Limeira, 04 fev. 2014a. Depoimento concedido a Wilson Ricardo Antoniassi de Almeida.

CARILE, Sonia Gabrielina Pascholati. Professora de 1993 a 2004. Terceiro Grupo Escolar. Limeira, 04 fev. 2014b. Depoimento concedido a Wilson Ricardo Antoniassi de Almeida.

CORREIO PAULISTANO. Jornal. Disponível em: <http://hemerotecadigital.bn.br/acervodigital/correio-paulistano/090972>. Acesso em: 12 mai. 2014.

FORTI, Regina Cristina Rebelato. Diretora da Escola desde 2011. Terceiro Grupo Escolar. Limeira, 24 jun. 2014. Depoimento concedido a Wilson Ricardo Antoniassi de Almeida.

GAZETA DE LIMEIRA. Jornal. Limeira-SP. Arquivo do Jornal Gazeta de Limeira. GRUPO ESCOLAR DE SANTA BARBARA D'OESTE. Livro Ponto do Pessoal. Santa Barbara D'Oeste-SP, 1920. Arquivo da Escola Estadual José Gabriel de Oliveira. . Livro de Registro de Nomeações e Licenças. Santa Barbara D'Oeste, 1924. Arquivo da Escola Estadual José Gabriel de Oliveira.

GRUPO ESCOLAR DR. FLAMÍNIO LESSA. Livro de Registro dos Diplomas de Habilitação no Curso Preliminar. Guaratinguetá, 1898. Arquivo do Museu Frei Galvão.

LIMA, Merchides Leonel. Funcionário de 2014 a 2016. Terceiro Grupo Escolar. Limeira, 12 abr. 2015. Depoimento concedido a Wilson Ricardo Antoniassi de Almeida.

LIMEIRA. Ofício de 05 de agosto de 1944. Livro Copiador de Ofícios. Prefeitura Municipal de Limeira. Arquivo da Prefeitura Municipal de Limeira.

LOPES, Carla de Cássia Ferreira. Aluna de 2013 a 2016. Terceiro Grupo Escolar. Limeira, 20 mar. 2014. Depoimento concedido a Wilson Ricardo Antoniassi de Almeida.

LUIZ, Nilza Aparecida. Aluna de 1954 a 1958. Terceiro Grupo Escolar. Limeira, 21 abr. 2014b. Depoimento concedido a Wilson Ricardo Antoniassi de Almeida.

MARCHESIN, Maria Célia Zaros. Professora de 1980 a 1995. Terceiro Grupo Escolar. Limeira, 04 fev. 2014. Depoimento concedido a Wilson Ricardo Antoniassi de Almeida.

MIGUEL, Ariadne Francisca Carrera. Professora substituta efetiva de 1956 a 1960.

Terceiro Grupo Escolar. Limeira, 10 abr. 2014. Depoimento concedido a Wilson Ricardo Antoniassi de Almeida.

MUSEU FREI GALVÃO. Arquivo. Inventário de Francisco das Chagas Santos, Cartório de 1으́́cio, Comarca de Guaratinguetá-SP, maço 157, de 23 de outubro de 1894. Arquivo. Inventário de Emília dos Reis Santos, Cartório de 2o Ofício, Comarca de 
Guaratinguetá, caixa 24-A, de 18 de setembro de 1928.

OLIVEIRA, Dinorá Piras de: Professora de 1980 a 1993. Terceiro Grupo Escolar. Limeira, 04 fev. 2014. Depoimento concedido a Wilson Ricardo Antoniassi de Almeida.

O LIMEIRENSE. Jornal. Limeira-SP. Centro de Memória Histórica de Limeira.

PEREIRA, Murilo Antonio Kühl. Aluno de 2012 a 2015. Terceiro Grupo Escolar. Limeira, 7 jun. 2014. Depoimento concedido a Wilson Ricardo Antoniassi de Almeida.

PORFIRIO, Ivanilda Maria Giusti. Professora desde 2009. Terceiro Grupo Escolar.

Limeira, 12 jun. 2014. Depoimento concedido a Wilson Ricardo Antoniassi de Almeida.

RAMOS, Anizia Lazara Pimentel. Funcionária de 1970 a 1976. Terceiro Grupo Escolar. Limeira, 21 jun. 2014. Depoimento concedido a Wilson Ricardo Antoniassi de Almeida.

RODRIGUES, Ana Paula De Michielli. Funcionária desde 2009. Terceiro Grupo Escolar. Limeira, 2014. Depoimento concedido a Wilson Ricardo Antoniassi de Almeida.

SANTOS, Iracy Nepomoceno dos. Professora de 1979 a 1995. Terceiro Grupo Escolar. Limeira, 04 fev. 2014. Depoimento concedido a Wilson Ricardo Antoniassi de Almeida.

SÃO PAULO (Estado). Decreto no 248, de 26 de julho de 1894. Aprova o regimento interno das escolas públicas. Disponível em:

<http://dobuscadireta.imprensaoficial.com.br/default.aspx?DataPublicacao=18940816\&Ca derno=Diario\%200ficial\&NumeroPagina=11105>. Acesso em: 21 ago. 2014.

. Lei no 374, de 3 de setembro de 1895. Providencia sobre o ensino das matérias do

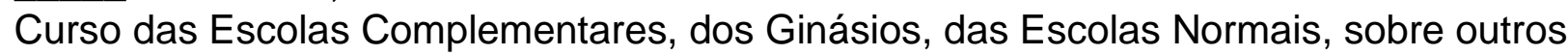
assumptos relativos, e cria como uma secção da Diretoria Geral de Instrução Pública um Almoxarifado marcando-lhe o pessoal e vencimentos. Disponível em:

<http://www.al.sp.gov.br/repositorio/legislacao/lei/1895/lei-374-03.09.1895.html>. Acesso em: 12 fev. 2014.

Decreto no 739, de 16 de fevereiro de 1900. Dispõe sobre pratica de ensino e expedição de diplomas de habilitação para o magistério a alunos de escolas complementares do Estado. Disponível em:

<http://www.al.sp.gov.br/repositorio/legislacao/decreto/1900/decreto-739-

16.02.1900.html>. Acesso em: 13 fev. 2015.

Requerimento despachado de 24 de dezembro de 1906. Disponível em:

<http://www.imprensaoficial.com.br/PortallO/DO/BuscaDO2001Documento_11_4.aspx?lin k=/1906/diario\%2520oficial/dezembro/27/pag_3159_5LJ5NTBVKG3HOeDFFK54LLHCD74 H.pdf\&pagina=3159\&data=27/12/1906\&caderno=Di\%C3\%A1rio\%20Oficial\&paginaordena cao=103159>. Acesso em: 01 mai. 2014.

. Decreto de 31 de janeiro de 1908. Disponível

em:<http://www.imprensaoficial.com.br/PortallO/DO/BuscaDO2001Documento_11_4.aspx ?link=/1908/diario\%2520oficial/fevereiro/04/pag_0329_FGMMBLROLH0LOe5HT̄H6SU94R Q09.pdf\&pagina=329\&data=04/02/1908\&caderno=Di\%C3\%A1rio\%20Oficial\&paginaorden acao=100329>. Acesso em: 13 jan. 2014.

Decreto de 17 de janeiro de 1910. Disponível em:

<http://www.imprensaoficial.com.br/PortallO/DO/BuscaDO2001Documento_11_4.aspx?lin k=/1910/diario\%2520oficial/janeiro/18/pag_0177_6M6KFFFAQ9URle1E69QDD268IGL6.pdf \&pagina $=177 \&$ data $=18 / 01 / 1910 \&$ caderno $=\mathrm{Di} \% \mathrm{C} 3 \% \mathrm{~A} 1 \mathrm{rio} \% 20 \mathrm{Oficial} \&$ paginaordenacao $=1$ 00177>. Acesso em: 22 ago. 2014.

Decreto de 23 de março de 1920. Disponível em:

<http://www.imprensaoficial.com.br/PortallO/DO/BuscaDO2001Documento_11_4.aspx?lin 
$\mathrm{k}=/$ 1920/diario\%2520oficial/marco/24/pag_1873_AUKHPCHCGI7S4e6KFO8P845B6DU.p df\&pagina $=1873 \&$ data $=24 / 03 / 1920 \&$ caderno=Di\%C3\%A1 rio\%20Oficial\&paginaordenacao $=101873>$. Acesso em: 12 fev. 2014 .

Decreto de 18 de janeiro de 1944a. Cria grupos escolares. Disponível em: <http://www.imprensaoficial.com.br/PortallO/DO/BuscaDO2001Documento_11_4.aspx?lin k=/1944/executivo/janeiro/19/pag_0001_21UCJ0G7EP3T5eBP010F35TUVU4.pdf\&pagina $=1 \&$ data $=19 / 01 / 1944 \&$ caderno=Executivo\&paginaordenacao $=100001>$. Acesso em: 10 jan. 2014.

Decreto no 14.147, de 23 de agosto de 1944b. Dá a denominação ao 3 Grupo Escolar de Limeira. Disponível em:

<http://www.al.sp.gov.br/repositorio/legislacao/decreto/1944/decreto-1414723.08.1944.html>. Acesso em: 02 jan. 2014.

Decreto no 17.698, de 26 de novembro de 1947. Aprova a Consolidação mandada elaborar pelo Decreto n. 17.211, de 13 de maio de 1947. Disponível em: <http://www.al.sp.gov.br/repositorio/legislacao/decreto/1947/decreto-1769826.11.1947.html >. Acesso em: 10 de mai. 2015.

Resolução no 443, de 25 de março de 1955a. Proíbe manifestações políticas de servidores públicos na prática de atos de suas funções e dá outras providências. Disponível em:

<http://www.imprensaoficial.com.br/PortallO/DO/BuscaDO2001Documento_11_4.aspx?lin k=/1955/executivo/marco/26/p1/pag_0001_3J9UHEDB4RKMTe0C81KHCl3MK0P.pdf\&pa gina $=1 \&$ data $=26 / 03 / 1955 \&$ caderno $=$ Executivo $\&$ paginaordenacao $=100001>$. Acesso em: 23 de no. 2014.

Ato SE no 29, de 16 de setembro de 1955b. Disponível em: <http://www.imprensaoficial.com.br/PortallO/DO/BuscaDO2001Documento_11_4.aspx?lin k=/1955/executivo/setembro/21/pag_0017_AASK96FOQ0BQDeF5GO0MOFSO6N6.pdf\&p agina $=17 \&$ data $=21 / 09 / 1955 \&$ caderno $=$ Executivo\&paginaordenacao $=100017>$. Acesso em: 21 nov. 2014.

Decreto no 25.014-A, de 13 de outubro de 1955c. Dá a denominação de "Professor Leovegildo Chagas Santos" ao Terceiro Grupo Escolar de Limeira. Disponível em: <http://www.imprensaoficial.com.br/PortallO/DO/GatewayPDF.aspx?link=/1955/executivo/ outubro/19/pag_0001_4ISVUIKNNS9DMe7RCH728HRK7J4.pdf>. Acesso em: 04 fev.2013.

Ato $n \circ$ 45, de 13 de maio de 1964. Ensino oficial reverencia o Padroeiro do Magistério. Disponível em:

<http://www.imprensaoficial.com.br/PortallO/DO/BuscaDO2001Documento_11_4.aspx?lin k=/1964/executivo/maio/14/p1/pag_0001_BE8ADFJLT6S13e5MJUB6F3NDJJI.pdf\&pagina $=1 \&$ data $=14 / 05 / 1964 \&$ caderno $=$ Executivo\&paginaordenacao $=100001>$. Acesso em: 13 mai. 2015.

Lei $n^{\circ} 1.245$, de 23 de dezembro de 1976. Determina que se comemore nos estabelecimentos públicos do Estado o dia dos respectivos patronos. Disponível em: $<$ http://dobuscadireta.imprensaoficial.com.br/default.aspx?DataPublicacao=19761224\&Ca derno=Poder\%20Executivo\&NumeroPagina=1 >. Acesso em: 23 nov. 2014.

Resolução SE no 33, de 11 de fevereiro de 1988. Institui nas Delegacias de Ensino, o arquivo do patrono. Disponível em:

<http://www.imprensaoficial.com.br/PortallO/DO/BuscaDO2001Documento_11_4.aspx?lin k=/1988/executivo\%2520secao\%2520i/fevereiro/12/pag_0001_6GDK3ACHED8D1e027L RA1CJR7J8.pdf\&pagina $=1 \&$ data $=12 / 02 / 1988 \&$ caderno $=$ Executivo $\% 20$ I\&paginaordenacao 
$=100001>$. Acesso em: 12 fev.2015.

. Lei no 14.707, de 08 de março de 2012. Dispõe sobre a denominação de prédios, rodovias e repartições públicas estaduais. Disponível em:

<http://www.al.sp.gov.br/repositorio/legislacao/lei/2012/lei-14707-08.03.2012.html>. Acesso em: 12 jan. 2015.

SELINGARDI, Paula Eduarda da Silva. Aluna de 2012 a 2015. Terceiro Grupo Escolar. Limeira, 12 mai. 2014. Depoimento concedido a Wilson Ricardo Antoniassi de Almeida.

SERVIÇO DE REGISTRO CIVIL DO 1 SUBDISTRITO DE GUARATINGUETÁ. Certidão de óbito, cujo registro está lavrado no livro C-0007, folhas 053, sob o número 544 . Guaratinguetá-SP, 1894.

. Certidão de óbito, cujo registro está lavrado no livro C-0045, folhas 002-V, sob o número 72. Guaratinguetá-SP, 1925.

. Certidão de óbito, cujo registro está lavrado no livro C-0048, folhas 013, sob o número 474. Guaratinguetá-SP, 1928.

SORG, Vanda Aparecida Francisco. Professora de 1976 a 1980 e de 1982 a 1995.

Terceiro Grupo Escolar. Limeira, 04 fev. 2014. Depoimento concedido a Wilson Ricardo Antoniassi de Almeida.

STEFANEL, Maria Claudia Nunes. Professora desde 2008. Terceiro Grupo Escolar. Limeira, 09 out. 2014. Depoimento concedido a Wilson Ricardo Antoniassi de Almeida.

SOUZA, Rosa Fátima de. Templos de civilização: a implantação da escopa primária graduada no estado de São Paulo: (1890-1910). São Paulo: Fundação Editora da UNESP, 1998. 302p.

TERCEIRO GRUPO ESCOLAR DE LIMEIRA. Mapa do Movimento. Limeira, 1944-1971. Arquivo da Escola Estadual Professor Leovegildo Chagas Santos.

VITTA, Jurandir Godoi. Aluno em 1959 e professor de 2006 a 2008. Terceiro Grupo Escolar. Limeira, 10 jun. 2014. Depoimento concedido a Wilson Ricardo Antoniassi de Almeida.

WILSON RICARDO ANTONIASSI DE ALMEIDA é Doutor em Educação pelo Programa de Pósgraduação em Educação da Universidade Federal de São Carlos, São Carlos, SP, Brasil e membro do Histedbr/Ufscar - Grupo de Pesquisa História, Sociedade e Educação no Brasil, da Universidade Federal de São Carlos, SP, Brasil.

Endereço: Rua Asme Abdalla Salibe, 408 - Jardim Residencial Granja Machado - 13485-210

- Limeira/SP - Brasil

E-mail: ricantoniassi@hotmail.com

Recebido em 07 de setembro de 2016.

Aceito em 13 de dezembro de 2016. 